\title{
Audit of ascertainment of deaths to children born in Cumbria, UK, 1950-89 through the NHS Central Register
}

\author{
H O Dickinson, L Parker, D Harris, B Botting, A Lawson
}

\begin{abstract}
Study objective-To evaluate the completeness of notification of deaths by the National Health Service Central Register (NHSCR) for England and Wales.

Design-Deaths for a birth cohort were ascertained through scanning the relevant volumes of NHSCR. Attempts were made to confirm these deaths and additional deaths were ascertained through searching local records. Logistic regression was used to investigate how the probability of a death being missed by NHSCR varied with the year of birth, age at death, sex, and social class.
\end{abstract}

Setting-Deaths up to the end of 1989 in the CA postal area among 264046 children born between 1950 and 1989 to mothers living in Cumbria.

Results-NHSCR originally ascertained 4139 deaths; local searches confirmed 3338 $(81 \%)$ of these and found an additional 342. Most deaths missed by the NHSCR were neonatal deaths in the 1950 s and 1960s. In the $1950 \mathrm{~s}, 31 \%$ of children who died in the neonatal period either were not entered on NHSCR or, if they were entered, there was no record of their death. For children born from 1970 onwards, ascertainment of deaths through NHSCR was over 99\% complete.

Conclusions-The NHSCR was started in 1948 for the administration of records of National Health Service patients. It seems that many babies who died soon after birth were not therefore recorded. In parallel with the increasing use of NHSCR for epidemiological purposes, there has been a substantial and continuing improvement in its clerical procedures since the mid 1960s.

(f Epidemiol Community Health 1997;51:438-442) Statistics,

St Catherine's House,

London

B Botting

Department of Occupational

Health and Medical

Statistics,

The Princess Royal

Building, Westlakes

Research Institute,

Whitehaven, Cumbria

A Lawson

Correspondence to:

Dr H O Dickinson.

Accepted for publication January 1997 checked hospital and other records in the region for the period. This process identified a number of deaths for which notification had not been received from NHSCR. As medical records in Carlisle and Whitehaven hospitals were more complete than for the rest of Cumbria, the NECCRU and NHSCR decided to carry out a collaborative audit of the ascertainment of deaths which had occurred in the area served by these hospitals, which corresponds closely to the CA postal area (see fig 1), to ascertain how many had been missed by NHSCR and why. The results were analysed with respect to the year of birth, age at death, sex, and social class.

\section{Methods}

The birth cohort comprised all children born between 1 January, 1950 and 30 September, 1989 to mothers resident in the area defined as Cumbria in the local government reorganisation of $1974 .^{3}$ The acquisition of the data and the data linkage have been described in detail by Parker et al. ${ }^{12}$ The live and stillbirth registers for Cumbria for the study period were obtained on microfilm from the Office for $\mathrm{Na}$ tional Statistics, formerly the Office of Population Censuses and Surveys (OPCS) and entered onto a database at NECCRU. The 264046 live births were linked to 7514 deaths which had occurred not only in Cumbria but throughout the United Kingdom and abroad.

The 4481 deaths occurring in this cohort in the CA postal area (see fig 1) before the end of 1989 were the subject of the audit. Deaths for the cohort were identified using the NHSCR, a division of OPCS based at Southport. As the master index of National Health Service patients for England and Wales, NHSCR's main purpose is to assist the health authorities (formerly family health service authorities) in the transfer of primary care medical records within the general practitioner network. As part of this administrative function it is routinely updated with details of patient births, deaths, name changes, movements between health authorities and related events, and so can be exploited as a unique epidemiological resource. ${ }^{4}$ Prior to 1990 , it was organised in transcript books structured by National Health Service number (allocated at birth registration) with a unique entry for each person. Each transcript book holds registrations for one registration area for a specific time period. Targeting the appropriate transcript books for Cumbrian births between 1950 and 1989 en- 
Table 1. Sources of ascertainment of deaths in the CA postal area of children born in Cumbria 1950-89

\begin{tabular}{|c|c|c|c|}
\hline & $\begin{array}{l}\text { Notified by } \\
\text { NHSCR }\end{array}$ & $\begin{array}{l}\text { Initially missed } \\
\text { by NHSCR }\end{array}$ & Total \\
\hline \multicolumn{4}{|l|}{ All deaths in cohort } \\
\hline Found in local records & 3338 & 342 & 3680 \\
\hline Not found in local records & $\begin{array}{l}\text { (c) } \\
801\end{array}$ & $\begin{array}{l}\text { (d) } \\
\text { Unknown }\end{array}$ & Unknown \\
\hline Total & 4139 & Unknown & Unknown \\
\hline \multicolumn{2}{|l|}{$\begin{array}{l}\text { Known deaths in cohort } \\
\text { Notified by NHSCR and found in local records }\end{array}$} & & $(\%)$ \\
\hline \multicolumn{2}{|l|}{ Initially missed by NHSCR but found in local records } & $\begin{array}{l}3338 \\
\text { (b) }\end{array}$ & (74) \\
\hline \multirow{2}{*}{\multicolumn{2}{|c|}{ Notified by NHSCR but not found in local records }} & 342 & (8) \\
\hline & & 801 & (18) \\
\hline \multicolumn{2}{|l|}{ Total } & 4481 & (100) \\
\hline
\end{tabular}

NHSCR $=$ National Health Service Central Register

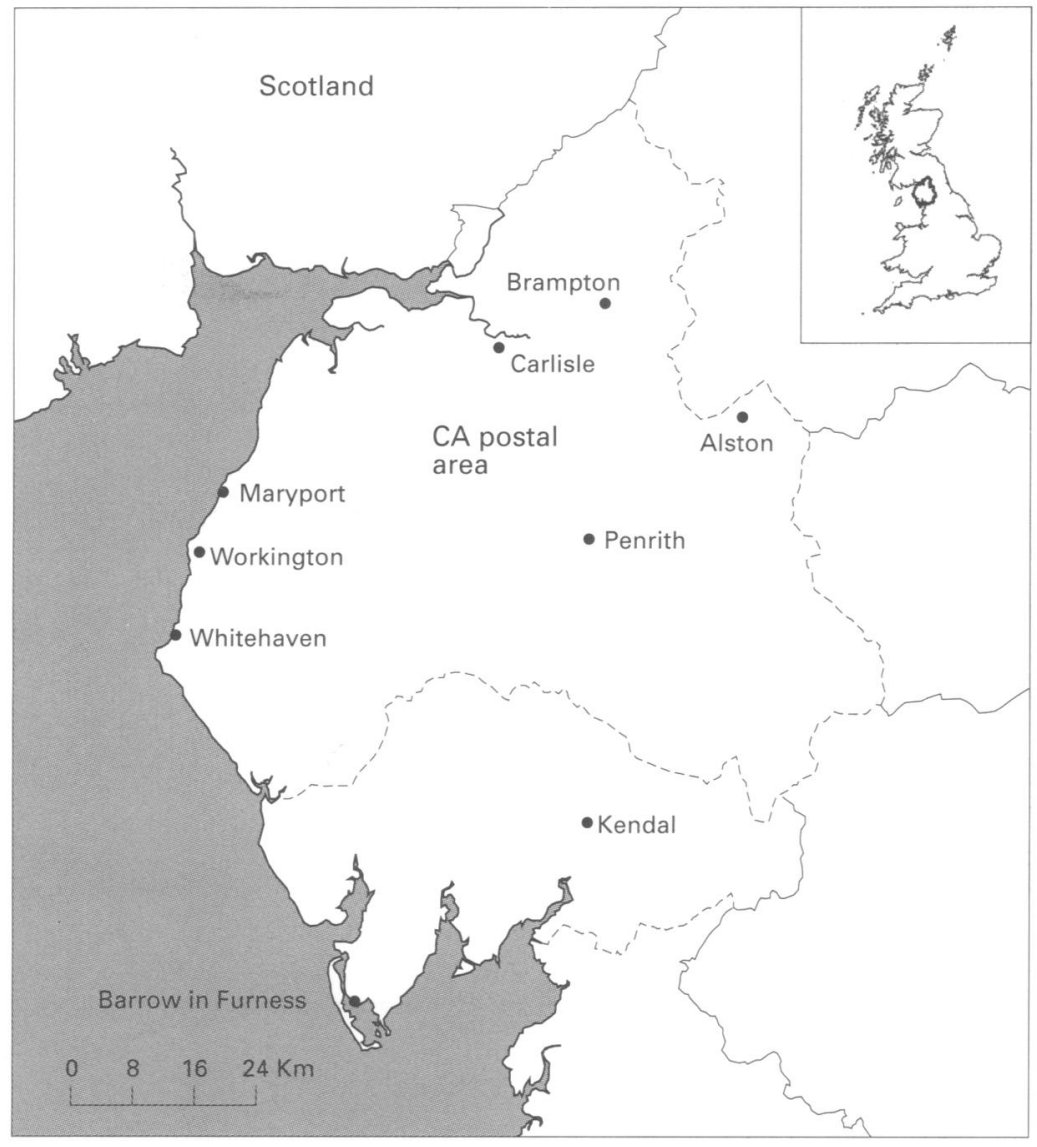

Figure 1 Map of Cumbria, showing the $C A$ postal area and locations of hospitals within the area where records were searched.

abled NHSCR to scan the relevant patient entries. Information on the death in the transcript book allowed the relevant death draft to be identified. This included deaths which occurred in Scotland, Northern Ireland, and overseas. These death drafts were forwarded to NECCRU where all information on them was entered onto the NECCRU Cumbrian database. The deaths were then linked to the corresponding births using computerised methods. ${ }^{12}$ Finally, the place of death was postcoded using Post Office directories and hence those which had occurred in the CA postal area were identified.

Hospitals within Cumbria (see fig 1), district general hospitals outside but close to Cumbria,

\section{KEY POINTS}

- The NHS Central Register has recorded virtually all the population of England and Wales since 1948: entries are flagged for major events including death, cancer, and emigration.

- In the 1950 s, many babies who died soon after birth were either not recorded on the register, or, if they were entered, there was no record of their death.

- From 1970 onwards, ascertainment of deaths through the Central Register was over $99 \%$ complete.

- Researchers can have confidence in the completeness of death ascertainment through the NHS Central Register except in extremely unusual circumstances.

and regional referral centres were then searched for records, eg post mortem reports, medical records, and maternity and children's ward registers, referring to deaths of children in the cohort. In addition to these hospital records, the Northern Region survey of infant deaths, ${ }^{5}$ the Oxford survey of childhood cancers, ${ }^{67}$ the Cumbrian archives and coroner's offices and vital statistics held by local departments of public health were also consulted.

For each death mentioned in these records of a child possibly born in Cumbria, the name (or mother's name), date of birth, date of death, and cause of death were recorded, if available. The NECCRU Cumbrian database was searched for each of these deaths, firstly among the deaths, secondly among the stillbirths and, if not found on either of these, among the live births. If the case was recorded as a live birth but not as a death, it was noted as a "missed death" and NHSCR was informed of all the details on the birth registration and of the details of the death as found in the local records. They responded by searching the OPCS death indices and forwarding the relevant draft. The details of these additional death drafts were entered onto the NECCRU Cumbrian database.

For deaths in the CA area which had originally been missed, NHSCR additionally supplied audit codes, which were also entered onto the NECCRU Cumbrian database, to indicate why the deaths had been missed.

The causes of death, as recorded on both the death drafts and the local records, were coded to ICD-989 by NECCRU. The occupation of the father, as recorded on the birth registration, was also coded by NECCRU and hence the associated social class was derived. ${ }^{10}$

Deaths in the cohort fall into one of four categories (see table 1) as follows:

(a) Confirmed deaths: notified by NHSCR and found in local records.

(b) Missed deaths: initially missed by NHSCR but found in local records.

(c) Unconfirmed deaths: notified by NHSCR but not found in local records.

(d) Unknown deaths: there is almost certainly a small number of deaths about which 
Table 2 Number of births for which local records were found (category (a)), as a proportion of the total number of deaths initially notified by National Health Service Central Register (NHSCR) (categories (a) and (c)) in relation to time period of birth

\begin{tabular}{|c|c|c|c|c|}
\hline $\begin{array}{l}\text { Time period } \\
\text { of birth }\end{array}$ & $\begin{array}{l}\text { No of deaths initially } \\
\text { notified by NHSCR } \\
\text { (a) }+ \text { (c) }\end{array}$ & $\begin{array}{l}\text { No of deaths initially notified by } \\
\text { NHSCR and found in local records } \\
\text { (a) }\end{array}$ & $\begin{array}{l}\text { Propo } \\
\text { found } \\
(95 \%\end{array}$ & $\begin{array}{l}\text { ion of deaths } \\
\text { n local records } \\
\text { CI) }\end{array}$ \\
\hline $\begin{array}{l}1950-59 \\
1960-69 \\
1970-89 \\
1950-89\end{array}$ & $\begin{array}{l}1720 \\
1395 \\
1024 \\
4139\end{array}$ & $\begin{array}{r}1227 \\
1162 \\
949 \\
3338\end{array}$ & $\begin{array}{l}0.71 \\
0.83 \\
0.93 \\
0.81\end{array}$ & $\begin{array}{l}(0.69,0.73) \\
(0.81,0.85) \\
(0.91,0.94) \\
(0.79,0.82)\end{array}$ \\
\hline
\end{tabular}

nothing was ascertained either from

NHSCR or from searches of local records. Although our primary concern was to describe missed deaths it was clearly important to examine whether those deaths found in local records were representative of all deaths. To explore this, the software package STATA ${ }^{11}$ was used to carry out a logistic regression ${ }^{12}$ to determine whether the probability of finding a death in local records was related to year of birth and age at death. This modelled the probability of deaths in categories (a) and (c) falling into the category (a) and hence allowed us to assess whether the subset of deaths for which local records had been found was an unbiased sample.

Having assessed the bias in the sample as fully as possible with this preliminary analysis, we then proceeded with the main analysis. To investigate how the probability of a death being missed by NHSCR varied with year of birth, age at death, sex and social class, a further logistic regression was carried out with these as the explanatory variables and whether or not a death had been missed by NHSCR as the outcome. This modelled the probability of deaths in categories (a) and (b) (confirmed and missed) falling into the category (b) (missed deaths).

Confidence intervals for proportions were calculated using the exact binomial method. ${ }^{11}$

\section{Results}

The audit focused on the 4481 deaths known to have occurred in the CA postal area. Local records were found confirming 3338 deaths ( $81 \%$ of those initially notified by NHSCR), and identified a further 342 which had originally been missed, see table 1 .

As a preliminary step, the possible bias in finding local records was assessed. Local records were more likely to be found for those born more recently (see table 2). Although local records were more also likely to be found for those who died at an earlier age, this effect was not significant after allowing for the time period of birth.

The main analysis was then carried out. The deaths which were missed by NHSCR but found through local searches (category (b)), were examined. The reasons why these deaths were missed and the numbers in each category affected are presented in table 3.

Logistic regression showed that both the time period of birth and age at death needed to be included in the statistical model describing the probability of a death being missed. The distribution of the deaths missed by NHSCR (category (b)) is shown in table 4 as a proportion of all deaths found in local records (categories (a) and (b) confimed and missed), by time period of birth and age at death. Overall, major under ascertainment was confined to children born before 1970 and affected mainly

Table 3 Categories of deaths, in the CA postal district only, missed by the National Health Service Central Register (NHSCR). Percentages are relative to the total number of deaths (3680) found by local searches

\begin{tabular}{|c|c|c|c|c|c|}
\hline \multirow[t]{2}{*}{ Reason death was missed } & \multirow[t]{2}{*}{ No } & \multirow[t]{2}{*}{$(\%)$} & \multicolumn{3}{|c|}{ Characteristics of people missed } \\
\hline & & & Age at death & Born & Died \\
\hline $\begin{array}{l}1 \text { Blank entry at NHSCR, ie no birth details ever transcribed } \\
2 \text { No death or Health Authority details recorded at NHSCR entry } \\
3 \text { No death recorded at NHSCR } \\
4 \text { No death recorded at NHSCR but death certificate now found } \\
5 \text { Death missed by clerical officer scanning NHSCR } \\
6 \text { Death recorded at NHSCR but details indecipherable } \\
7 \text { Death recorded at NHSCR but no date of death noted } \\
8 \text { No birth certificate traced and birth not recorded at NHSCR. } \\
\text { Total }\end{array}$ & $\begin{array}{r}70 \\
139 \\
13 \\
15 \\
64 \\
12 \\
22 \\
7 \\
342\end{array}$ & $\begin{array}{l}(1.9) \\
(3.8) \\
(0.4) \\
(0.4) \\
(1.7) \\
(0.3) \\
(0.6) \\
(0.2) \\
(9.3)\end{array}$ & $\begin{array}{l}\text { Mainly neonatal } \\
\text { Mainly neonatal } \\
\text { All ages } \\
\text { All ages } \\
\text { All ages } \\
\text { Mainly infant } \\
\text { Early neonatal } \\
\text { Early neonatal }\end{array}$ & $\begin{array}{l}1950-64 \\
1950-67 \\
\text { Mainly } 1951-61 \\
1952-68 \\
1950-84 \\
1950-54 \\
1950-64 \\
11952-75\end{array}$ & $\begin{array}{l}1950-64 \\
\text { Mainly } 1952-68 \\
\text { Mainly } 1953-79 \\
\text { Mainly 1952-65 } \\
\text { All years } \\
1951-55 \\
1950-64 \\
1952-75\end{array}$ \\
\hline
\end{tabular}

Table 4 Numbers of deaths missed by National Health Service Central Register (NHSCR) (category (b)), as a proportion of deaths found in local records (categories (a) and (b)) in relation to time period of birth and age at death

\begin{tabular}{|c|c|c|c|c|}
\hline Time period of birth & Age at death & $\begin{array}{l}\text { No of deaths found } \\
\text { in local records } \\
\text { (a) }+ \text { (b) }\end{array}$ & $\begin{array}{l}\text { No of deaths missed } \\
\text { by NHSCR } \\
\text { (b) }\end{array}$ & $\begin{array}{l}\text { Proportion of deaths } \\
(95 \% \text { CI })\end{array}$ \\
\hline $1950-59$ & $\begin{array}{l}<28 \text { days of age } \\
>=28 \text { days and }<1 \text { year of age } \\
>=1 \text { year of age } \\
\text { All ages }\end{array}$ & $\begin{array}{r}677 \\
416 \\
398 \\
1491\end{array}$ & $\begin{array}{r}211 \\
42 \\
12 \\
265\end{array}$ & $\begin{array}{l}0.31(0.28,0.35) \\
0.10(0.07,0.13) \\
0.03(0.02,0.05) \\
0.18(0.16,0.20)\end{array}$ \\
\hline $1960-69$ & $\begin{array}{l}<28 \text { days of age } \\
>=28 \text { days and }<1 \text { year of age } \\
>=1 \text { year of age } \\
\text { All ages }\end{array}$ & $\begin{array}{r}658 \\
309 \\
263 \\
1230\end{array}$ & $\begin{array}{r}42 \\
19 \\
7 \\
68\end{array}$ & $\begin{array}{l}0.06(0.05,0.09) \\
0.06(0.04,0.09) \\
0.03(0.01,0.05) \\
0.06(0.04,0.07)\end{array}$ \\
\hline $1970-89$ & $\begin{array}{l}<28 \text { days of age } \\
>=28 \text { days and }<1 \text { year of age } \\
>=1 \text { year of age } \\
\text { All ages }\end{array}$ & $\begin{array}{r}557 \\
364 \\
38 \\
959\end{array}$ & $\begin{array}{l}5 \\
4 \\
0 \\
9\end{array}$ & 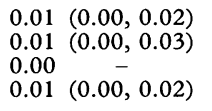 \\
\hline $1950-89$ & All ages & 3680 & 342 & $0.09(0.08,0.10)$ \\
\hline
\end{tabular}


Table 5 Numbers of deaths found in local records by cause of death. Each death may fall into several categories of ICD-9 codes as there may have been several causes specified

\begin{tabular}{|c|c|c|c|c|}
\hline \multicolumn{2}{|c|}{ Cause of death } & \multirow{2}{*}{$\begin{array}{l}\text { No of deaths } \\
\text { found in local } \\
\text { records } \\
\text { (a) }+ \text { (b) }\end{array}$} & \multirow{2}{*}{$\begin{array}{l}\text { No of deaths } \\
\text { missed by } \\
\text { NHSCR } \\
\text { (b) }\end{array}$} & \multirow{2}{*}{$\begin{array}{l}\text { Proportion of } \\
\text { deaths missed } \\
(95 \% \mathrm{CI})\end{array}$} \\
\hline ICD-9 code & Category & & & \\
\hline $140-239$ & Neoplasms & 232 & 5 & $0.02(0.01,0.05)$ \\
\hline $740-759$ & Congenital anomalies & 1125 & 71 & $0.06(0.05,0.08)$ \\
\hline $760-779$ & $\begin{array}{l}\text { Conditions originating } \\
\text { in the perinatal period }\end{array}$ & 2188 & 243 & $0.11(0.10,0.12)$ \\
\hline $800-999$ & Injury and poisoning & 820 & 37 & $0.05(0.03,0.06)$ \\
\hline $\begin{array}{l}0-139 \\
240-739\end{array}$ & Other & 1851 & 75 & $0.04(0.03,0.05)$ \\
\hline
\end{tabular}

$780-799$

NHSCR $=$ National Health Service Central Register

those born between 1950 and 1964, especially those who died in the neonatal period. The probability of a death being missed decreased steeply with year of birth to virtually zero in the $1980 \mathrm{~s}$. There was no evidence that the probability of NHSCR missing a death reflected the social class of the parents. There was some indication, short of significance $(p=$ 0.053 ) that female deaths were more likely to be missed, but since there was no significant interaction between sex and the age at death, as might be expected if female deaths were missed due to a change of name on marriage, this is likely to be a chance finding.

To investigate whether missed deaths were more likely to be due to particular causes, the numbers of deaths were summarised by cause, as reported on the death certificates and also on local records, see table 5 .

There was one neonatal death of a foundling in the CA postal area for which it was impossible for OPCS to find a birth draft. For seven further neonatal deaths, the birth of the child did not appear to have been registered.

\section{Discussion}

A birth cohort study such as this allows precise estimates of the probability of deaths in early life being missed by NHSCR. However, as follow up has so far continued only until the end of 1989, when the oldest members of the cohort would be aged 40 years, it does not allow estimates of the probability of missed deaths in middle or later life.

As shown in table 1 , confirmative local records were not found for $18 \%$ of the deaths occurring within the audited area which were notified by NHSCR. The question arises as to whether the deaths found in local records were in any way a biased sample. Table 2 shows that failure to find local records was concentrated among children born in earlier years. As these were also the children for whom deaths were most likely to be missed (see table 4), we conclude that we are likely to have underestimated the true number of deaths missed by NHSCR, especially in early years, since a larger proportion of these deaths would not be found by either route of ascertainment.

Table 3 shows the various reasons why deaths were missed. The main areas of concern relate to neonatal deaths in the 1950 s (categories 1 and 2). A possible explanation for the blank entries (category!) is that registrars of births may have notified NHSCR of the number of births in their subdistrict each quarter, resulting in an allocation of NHS numbers and the reservation of a corresponding number of blank lines on the NHSCR, but the actual details of each child may only have been entered on the line reserved after he or she was registered with an NHS general practitioner. If this was the practice, children who died in the neonatal period and so had no contact with a general practitioner would never have had their details transcribed onto the NHSCR. For the children in category 2, although details of the child's birth were entered on the NHSCR, no further details, either of the health authority of the child's general practitioner or of the death of the child, were recorded. The number of cases in categories 1 and 2 suggests that there may have been a policy in that era of not recording at NHSCR details of those children known to have died soon after birth. In terms of National Health Service administration, of course, there would have been little value in doing so. It must also be noted that epidemiological studies using the NHSCR did not commence until some years later and it would have taken considerable foresight to anticipate a study such as the present one at that time.

The remaining categories of missed deaths affected all ages. If the identifying particulars given by the informant of the death differed from those held by NHSCR, there may have been a failure to match the death to a birth on NHSCR. The proportion of deaths missed during the scanning process (category 5 ) is of the order one might reasonably expect from an entirely clerical exercise in these much accessed and hand transcribed ledgers, many of which are over 40 years old.

The higher proportion of missed deaths reporting "conditions originating in the perinatal period" as a cause is consistent with the predominance of deaths of neonates among missed deaths (see table 5).

The question arises as to what extent mortality studies which rely on NHSCR are likely to be biased by missed deaths. The present study is unusual in its reliance on visual scanning of the NHSCR. Retrospective studies more typically require the tracing of individual study members whose personal details are submitted by the researcher. For prospective studies, individuals may be flagged on NHSCR so that the researcher is notified of any future event, such as death, cancer or emigration. With the exception of the 70 cases with a blank entry at the NHSCR and the 22 cases with no date of death noted (see categories 1 and 7 of table 3), all other categories of missed deaths, (6.8\% of all deaths), would be pertinent to both tracing and flagging studies. There is no reason to expect that national or regional statistics for deaths, including neonatal deaths, are underestimated due to the problems identified in the present study, as they are derived from counts of births and deaths independently of NHSCR.

The NHSCR was computerised in 1991 and much of the potential for human error has now been eliminated. Many of the updating and 
event notification processes are automated. Although a formal review of the impact of computerisation has not taken place as yet, the effect on data quality is generally regarded to have been extremely positive. In particular, the difficulties of missed death registrations should be substantially reduced for prospective studies.

There have been two previous studies of completeness of ascertainment of deaths using NHSCR.

Hawkins et $a l^{14}$ evaluated the completeness of ascertainment of deaths from cancer between 1953-88 of children under 15 years old. A total of 7379 children known to have developed cancer but not known to have died within 5 years of diagnosis were flagged at NHSCR, who failed to notify researchers of $4.2 \%$ of subsequent deaths, $3.2 \%$ due to clerical error and $1.0 \%$ because the NHSCR noted a live posting for the child. The comparable figures for the present study are much lower: $1.7 \%$ and $0.4 \%$ respectively.

Darby $e t a l^{15}$ have evaluated the completeness of follow up using the NHSCR for a cohort of 43055 men who served abroad in the armed forces in the 1950s and 1960s. Their study is complementary to the present one in that all the men in the former would have been in their mid-40s or older, whereas none of the people in our study was over 40 . Using Department of Social Security records for additional tracing, Darby et al found that NHSCR had missed $4.7 \%$ of all deaths, significantly less than the $9.3 \%$ of deaths missed in the current study, but the reasons for deaths being missed are likely to be different in the two studies because of the different age distributions of the cohorts. If we exclude categories $1,2,5$, and 8 of the missed deaths in table 3, which affect mainly neonates, we find that a remaining $2.8 \%$ of deaths were missed, significantly less than the $4.7 \%$ missed in the study of Darby et al. This may be because people who join the armed forces are difficult to follow up as they tend to be a highly mobile population.

While the present study clearly highlights some weaknesses in the integrity of NHSCR data, particularly in the $1950 \mathrm{~s}$ and $60 \mathrm{~s}$, the findings must be seen in context. The current project is unusual in approach, scope and level of interest in neonatal deaths from the 1950s. NHSCR has recorded virtually all the population of England and Wales since 1948. The only group likely to be excluded is those not born in the United Kingdom who have not registered with a National Health Service general practitioner. Hence NHSCR must constitute in practice the largest population based epidemiological register in the world. Over 500 epidemiological studies encompassing some 2.5 million people are successfully using the Office for National Statistics (formerly OPCS) medical research services. Much of this work of international renown would be impossible without the NHSCR. The current study accessed an archive of historical manual records. The fact that projects of this scale and complexity could be conducted at all on a largely clerical basis is remarkable and a testament to the commitment and skill of those involved.

Ethical approval for this study was obtained from West Cumbria, South Cumbria, East Cumbria, Newcastle and Manchester Area Health Authorities. Permission to use OPCS records was obtained from The Chief Medical Statistician of OPCS.

We thank the medical, nursing, and administrative staff a hospitals within Cumbria and at regional centres for allowin us access to their records. We are grateful to Mr Julian Smith for substantial computing assistance and to $\mathrm{Mr}$ Trevor Dumme for producing figure 1 .

We would like to thank the staff at the Office for Nationa Statistics, in particular Mrs Tracey Clayton, and staff at the North of England Children's Cancer Research Unit of the University of Newcastle upon Tyne, in particular Mrs Katharine Kirton and Mrs Jane Salotti, for their meticulous searches.

We are grateful to the North of England Children's Cancer Research Fund for the ongoing support it gives to the North of England Children's Cancer Research Unit, Newcastle.

We thank Dr Tom Sorahan and Dr Estelle Gilman at the University of Birmingham for extracting Cumbrian-born cancer cases from the Oxford Survey of Childhood Cancers.

We thank the anonymous referees for their careful reading of the manuscript and for their helpful suggestions.

This article contains material which is Crown Copyright and is reproduced with the permission of the Office for National Statistics.

Funding: this study was supported by the United Kingdom Coordinating Committee for Cancer Research (who funded HOD), and Westlakes Research Institute (who funded HOD and $A L)$.

Conflicts of interest: HOD, LP, AL, none. $\mathrm{DH}$ and $\mathrm{BB}$ are employees of the Office of National Statistics whose records were the subject of the audit.

1 Parker L, Craft AW, Smith J, et al. Geographical distribution of preconceptional radiation doses to fathers employed at the Sellafield nuclear installation, West Cumbria. $B M$ 1993;307:966-71.

2 Parker L, Dickinson HO, Smith J, et al. The creation of database of children of workers at a nuclear facility-an exercise in record linkage. Applied Occupational and En vironmental Hygiene 1997;12:40-45.

3 Compton E. Great Britain: Local Government Boundary Commission for England reports. London: HMSO, 1972.

4 Botting B, Reilly H, Harris D. Use of Office of Population Censuses and Surveys records in medical research and clinical audit. Health Trends 1995;27:4-7.

5 Northern Regional Health Authority. Collaborative survey of perinatal late neonatal and infant death in the northerm region, 1989. Newcastle upon Tyne: Northern Region Health Authority, 1989.

6 Knox EG, Stewart AM, Kneale GW, Gilman E A. Prenata irradiation and childhood cancer. F Radiol Prot 1987;7: 177-79.

7 Stewart AM, Webb J, Hewitt D. A survey of childhood malignancies. BMF 1987;i,1495-1508.

8 World Health Organization. Manual of the international clas sification of diseases. Vol 1. Geneva: World Health Organisation, 1977

9 World Health Organization. Manual of the international clas sification of diseases. Vol 2. Geneva: World Health Organization, 1978.

10 Office of Population Censuses and Surveys. Standard occupational classification. Vols 1, 2, 3. London: HMSO, 1990

11 Stata Corporation. Stata statistical software: release 4.0. Texas Stata Corporation, 1995.

12 Breslow NE, Day NE. Statistical methods in cancer research. Volume 2-The design and analysis of cohort studies. Lyon: International Agency for Research on Cancer, 1987.

13 Rothman KJ. Modern epidemiology. Boston/Toronto: Little, Brown and Company, 1986.

14 Hawkins MM, Swerdlow AJ. Completeness of cancer and death follow-up obtained through the NHSCR for Eng death follow-up obtained through the NHSCR

15 Darby SC, O'Hagan JA, Kendall GM, Doll R, Fell TP, Muirhead CR. Completeness of follow up in a cohort study of mortality using the United Kingdom NHSCR and records held by the Department of Social Security. $\mathcal{F}$ Epidemiol Community Health 1991;45:65-70. 